\title{
The Neighborhood Unit: Effective or Obsolete?
}

\author{
Nahyang Byun*1, Youngjun Choi ${ }^{2}$ and Jaepil Choi ${ }^{3}$
}

\author{
${ }^{1}$ Ph.D., Department of Architecture and Architectural Engineering, Seoul National University, Korea \\ ${ }^{2}$ Ph.D. Candidate, Department of Architecture and Architectural Engineering, Seoul National University, Korea \\ ${ }^{3}$ Professor, Department of Architecture and Architectural Engineering, Seoul National University, Korea
}

\begin{abstract}
This study attempts to verify the validity of the neighborhood unit theory in Korea and interpret its meaning. In Korea, Perry's neighborhood unit theory has been applied to new cities and housing block plans as a design principle since its introduction. While the theory has been actively applied to New Town developments throughout the world, it has also faced criticisms. This paper begins with the question 'Does Perry's theory still have viability in Korea?' First of all, this research reviewed the major contents and corresponding examples of Perry's theory. In attempts to answer this question, major contents of the controversies were summarized historically, along with reviews on the background of how Perry's theory was introduced. This is followed by examinations of applications of the neighborhood unit theory in Korea. Additionally, solutions regarding criticism of the theory were diagnosed. It was also pointed out that although there was a time that Perry's theory was applied uniformly during socioeconomic changes in Korea, there were efforts to overcome the limitations of this theory. As a result, it was found that the neighborhood unit theory still viably suggests basic design principles for various types of planning from residential planning to life zone planning.
\end{abstract}

Keywords: neighborhood unit; Clarence Perry; physical design; residential planning; apartment complex

\section{Introduction}

Clarence A. Perry, American sociologist and urban planner, provided the concept of the neighborhood unit as a composition of a community. When it was first presented in the 1920s, it gained great attention as an innovative design theory. Since then, Perry's theory has become a common design principle that is naturally considered in community planning. Acting as an important design principle, it has been practiced in housing block construction and in new city plans around the world. It is also true that the theory has been criticized for various reasons.

There are many reasons why this study paid attention to Perry's 90-year-old theory. First of all, the neighborhood unit theory has acted as a strong design paradigm for a long time in the field of housing block construction and city planning. Additionally, there was a need to review, in the context of the

*Contact Author: Nahyang Byun, Ph.D. Candidate,

Department of Architecture and Architectural Engineering,

Seoul National University, 39-511, 1 Gwanak-ro,

Gwanak-gu, Seoul, 151-74, Korea

Tel: +82-2-880-8869 Fax: +82-2-871-5518

E-mail: nhcloud@snu.ac.kr

(Received April 7, 2014 ; accepted July 19, 2014)
Korean built environment, the process of how Perry's theory has been applied and the effects it has had on housing block. It was also important to rethink the neighborhood unit theory and its meaning in order to find a new paradigm of housing block construction and planning in Korea. Therefore, this study starts from the question 'Is Perry's theory still useful in Korea?' and 'Does Perry's theory still have viability in Korea?' The purpose of this study is to verify the validity of the neighborhood unit theory in Korea and interpret its meaning.

The goal of this research, first of all, is to review Perry's theory along with examples of its application. This will be followed by a review of the theoretical debate that has been made regarding the theory. With a three-stage timeline set according to the social and economic changes in Korea, (stage 1: Introduction of Perry's theory, stage 2: Perry's theory in the period of expansion, and stage 3: Application of Perry's theory in the 21 st century.) we look into the outputs and applications of the neighborhood unit theory in Korea. By looking into some cases Perry's theory will be understood, both in terms of the Korean context, and its uniqueness. Finally, solutions to the problems of Perry's theory are diagnosed. 


\section{The Neighborhood Unit as a Design Paradigm \\ 2.1 Perry's Theory}

Perry set up the concept of neighborhood unit in 1929 and proposed to compose communities accordingly. The theory has become the base of design principles and a design paradigm for the development of local communities. It has been used in many housing block constructions and new town development plans and become an established design theory. This theory proposes a housing block composition principle based on population. It suggests 6 basic principles of spatial planning for housing blocks; size, boundary, open space, institution, local shop, and internal street system.

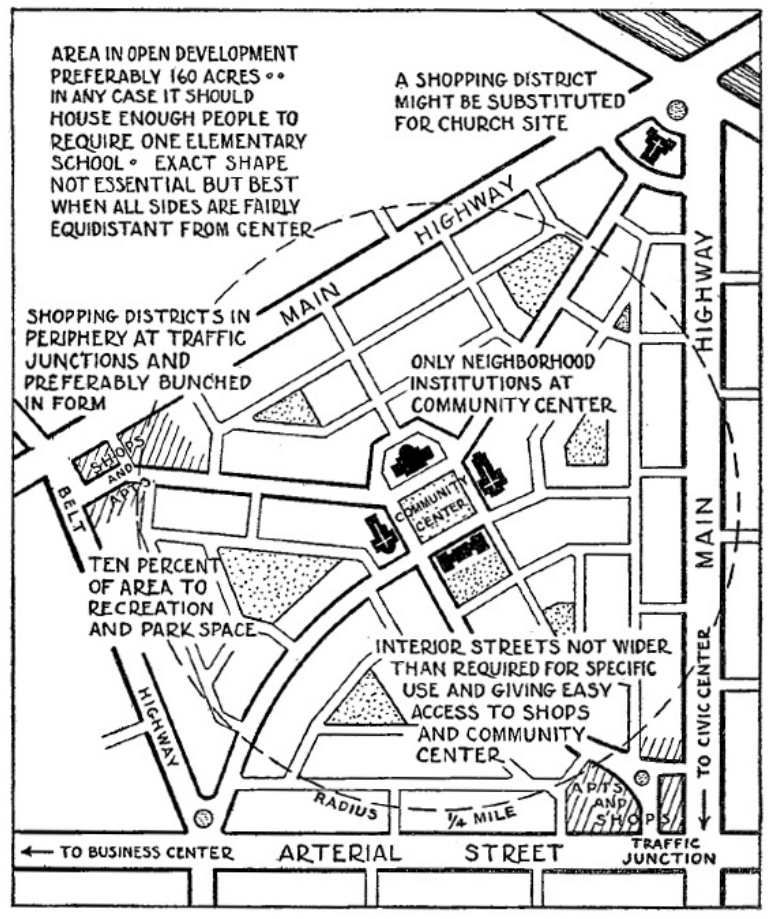

Fig.1. Concept of the Neighborhood Unit (Perry, 1966)

The neighborhood unit theory provides a planning guideline of space and facilities that can support a routine life within a spatial boundary. A neighborhood unit is a block surrounded by a convenient internal transportation network and trunk roads. A block is developed to have a size optimal to maintain an elementary school. According to Perry, the size of a neighborhood unit is an area of 160 acres (65ha) and population density of 37.5 persons/acre. It is a housing block where 3,000 9,600 people, with a maximum limit of 10,000 people, live around an elementary school with $1,000 \sim 1,600$ students in an area with a diameter of $1 / 2$ mile $(800 \mathrm{~m})$. In other words, Perry's neighborhood unit can be characterized as a neighborhood around an elementary school with its boundary defined by trunk roads. Internally, it distinguishes paths for pedestrians and roads for cars through classification of land use. Neighborhood units compose self-sufficient local communities assuming a city grows and develops based on the basic unit.

\subsection{Controversy Surrounding Perry's Theory}

Perry's neighborhood unit theory has been widely used for the basic physical planning of cities and housing blocks as well as for community composition. However, there have been criticisms and evaluations from various perspectives, too. In this study we will investigate the debate surrounding the theory.

In the USA, the theory has received criticism since the late 1940s, with sociologists having raised questions about its preconditions. They criticized the determinist perspective that physical environments were the deciding factors to the quality of life. They addressed the fact that a neighborhood could not only be explained by physical design factors such as layout, boundary, shape of the neighborhood, and spatial arrangements. Although the concept of neighborhood unit played an important role in the composition of local community and residents' perception of belonging in the 1920s, people's lives which were proposed in the neighborhood unit turned out to be different because people's lives became more complicated and diversified as time went by. (T. Banerjee and W. Baer, 1984)

For this reason, based on a thorough evaluation of its problems, new and developed design principles were explored. Lee (1996) reviewed that neighborhood unit theory still has theoretical clarity as an efficient unit of housing block development. However, it is emphasized that it is not essential or desirable to be the one and only model for planning housing blocks, and that it should be considered as one of the many different shapes of living environmental units. Lee placed importance on the alternative theories following the neighborhood unit theory as they provide clues for a new design paradigm despite the fact that they only remained as a plan or had some other problems.

On the one hand, Silver (1985) reviewed discourses on Perry's neighborhood unit theory by evaluating the effects of the theory during three periods divided according to historical perspectives; 'the 1880 s to 1920 s, ' '1920s to 1960 s', and '1960s and 1970 s. He mentioned that the neighborhood unit theory resulted in a self-sufficient community and social homogeneity among neighbors, despite its attempt to supplement and compensate existing neighborhoods instead of making new ones.

There has not been a new design theory that thoroughly solves the problems of Perry's neighborhood unit theory. Studies identify theoretical problems by surveying residents living in housing blocks where the neighborhood unit theory was applied or by evaluating the validity of the applications that were made. Those studies showed that modifications of the physical unit are required or that there had not been enough considerations concerning the social relations of residents from the perspective of community composition. There have been some studies that proposed alternative design concepts which supplemented insufficient or unconsidered parts. 
In the 1960's, however, America witnessed what is called the 'white flock,' where the majority of the white population moved to private houses in the suburban areas. One contributing factor to this change was the distribution of cars. With the increased use of cars, the pedestrian life and compact living zone envisioned by Perry rapidly became obsolete.

Nevertheless, Perry's theory has a historical importance and meaning in housing block and city planning as a design principle, due to its ubiquitous utilization in urban residential neighborhoods. Lawhon (2009) reviewed the theoretical background and historical importance of the neighborhood unit theory and the effects on ideology composition and development of the concept of neighborhood from the perspective of institutional and social backgrounds and physical designs. In particular, he diagnosed criticisms concerning physical determinism and its effects in the field of housing block planning. As a result, the neighborhood unit was found to be a physical model providing an opportunity for various interactions within the neighborhood.

The discourses on neighborhood unit theory can be summarized as follows; 1) It is a unit considering physical perspectives excluding social perspectives, and 2) It composes a self-sufficient closed community. While the former clearly proposes a physical unit of the planning principle, it failed to consider social perspectives. The latter results from a spatial configuration that is inevitably self-sufficient and closed.

We will now review how the neighborhood unit theory was introduced and applied to housing projects in Korea. Also reviewed will be how the two problems that rose against the neighborhood unit theory in early times have been resolved in Korea.

\section{Ramifications of Perry's Theory in Korea 3.1 Introduction of the Theory}

It is not clear when the neighborhood unit theory was first introduced in Korea. One can only guess the time of understanding and application of this theory through development projects and their plans in Korea after Perry published his neighborhood unit theory. Kwon and Jeon (2011) relatively and clearly specified the time and situation when neighborhood unit theory had its first influence on colonial Korea. He analyzed the 'Land Division Reorganization Plan' materials published from 1928 to 1938 based on the items proposed by the neighborhood unit theory. Accordingly, he estimated that those involved with the Seoul City Plan had perceived a concept similar to the neighborhood unit theory since the late 1920s. He specified that there was a clear understanding of the neighborhood unit theory no later than the year 1938 . He compared land reorganization project areas known to be planned before 1940 (the Donam, Daehyun and Youngdeungpo Districts) with housing land management project areas known to be planned after 1940 (the Shinchon, Sangdo and Keumho Districts) and the Seoul City Plan Street Network Map showing the practice in 1953. The effects of the neighborhood unit theory were similarly shown, which showed that the theory had affected housing plans in Seoul to some extent since the late 1930s.

Afterwards, discussions that housing land should be developed based on the neighborhood unit emerged among the planners of the Korea National Housing Corporation. It was the Hangang Block, constructed during the 1960s, in which the theory first materialized. The Hangang Mansion (1970), the Hangang Foreigners' Apartment (1970), and the Hangang Private Apartment (1971) were constructed to create a housing block with schools, local shops, and convenience facilities located in the center of the district. The method to create a life zone of each block by placing schools and local shops in the center shows the characteristics of the neighborhood unit theory. Additionally, there is a written record, "The concept of neighborhood was first introduced by the Hangang Apartment Block." (Korea National Housing Corporation, 1979) However, Kang et al. (1999) commented that the claim that it was planned by the neighborhood unit theory was simply from the judgment made only by studying the results. They commented that the Hangang Apartment Block was not thoroughly planned in advance and the development process was not consistent, either.

\subsection{Perry's Theory in the Expansion Period (1970's to 1990 's)}

Interestingly, planning principles of the neighborhood unit theory can be found in large-scale apartment complex projects. The institutional and legislative framework was established in Korea in the 1960s and 1970s. Afterwards, with the participation of civil companies, large-scale apartment blocks were built. At this time, the neighborhood unit theory became a major design theory applied to the block plan. To answer the question 'Where does the sample model of the Korean apartment block come from?' Park (2013) used the records of the Korea National Housing Corporation. In "Status of Housing Situation in Korea (1965)", diagrams showing Perry's theory, Plan of Hook New Town in the UK, London and New York City Plans, and German cases that Japanese planners referred to were explained in detail with diagrams. Here, the size of housing blocks and supply facilities were proposed in the form of tables. In essence, physical dimensions used in apartment blocks were not much different from those proposed by Perry. In most Korean apartment blocks of sufficient size, there is an elementary school inside of or near the block with local shops in the apartment block surrounded by trunk roads. Vehicles passing the block are controlled. In other words, physical design elements explaining neighborhood unit (size, boundary, open space, institution, local shop, internal street system) are applied in Korean apartment blocks. 


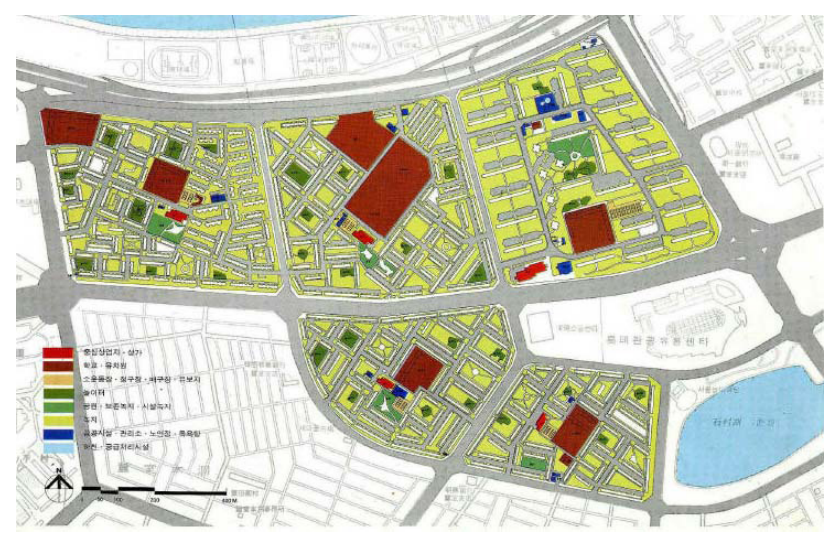

Fig.2. The Jamsil Apartment Complexes (Korea National Housing Corporation, 1975)

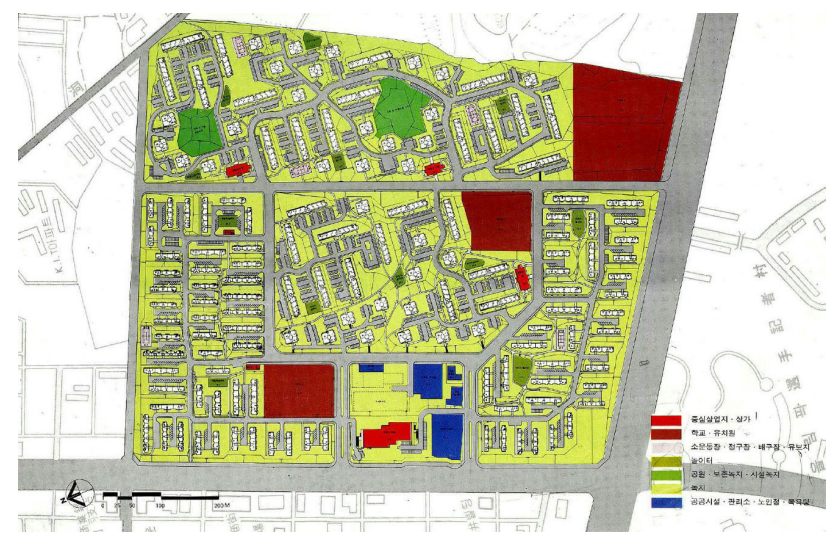

Fig.3. The Dunchon Apartment Complexes

(Korea National Housing Corporation, 1975)

The Jamsil Apartment Block is known to have followed the principles of the neighborhood unit theory faithfully. It planned a life zone as a housing block by selecting the method to concentrate facilities such as local shops, administration office, playground, and a school in the center of the block. Each block is surrounded by trunk roads while passing traffic was prohibited in the block. In Block V, local shops were planned to face the roads with the intention to make them the main retail district of the Jamsil area. The Jamsil Apartment Block has been criticized that it is a closed block because of the self-completeness of planning without connectivity between sub-blocks and spaces for the whole. This has to do with the fact that the streets, both boundary and internal, lacked pedestrian activity. Internally, the site was covered by parking lots while the green areas were located segregated from the building entrances. However, such planning principle has been continuously applied to housing blocks planned afterwards.

The Dunchon Block was planned with intentions to overcome the limitations identified in the Jamsil Block. (1979-1980) The Dunchon Block was composed of 5 sub-blocks. It was designed to be a large block without boundaries between sub-blocks. However, it did not have sufficient facilities required in a large block and became a transient body that did not completely overcome the problems of the Jamsil Block. (Lee et al., 1997, Kang et al., 1999)

Housing blocks and new towns in the 1980s were not as closed as those of the 1970s that followed the neighborhood unit theory. This is because they came to perceive the necessity of organic connection with city space. (Jeon et al., 2008) In the Gwacheon New Town Plan (1980-1984), the city was divided into 5 neighborhood units, which have sub-units respectively. However, the connection between the shopping district and each neighborhood was insufficient. Another representative example is the Mokdong New Town Plan. (1983) It was planned to have a linear center so that each spatial unit can be connected while it maintains its openness and hierarchy in each life zone. On the other hand, the Sanggye New Town Plan (1985) can be differentiated from the Mokdong New Town Plan in that it raised questions about the hierarchical composition of life zones. It composed life zones around the streets and preplanned trials to prevent each block from being a separate closed space. (Kang et al. 1999) Additionally, the Asia Seonsuchon (1986) and the Olympic Seonsuchon (1988) were planned through a housing competition as these cases showed developed planning techniques.

The Bundang New City (1989-1994) was planned as a large life zone with a children's park, not local shops, placed at the center. Local shops were placed in the area where various life zones overlapped. Around the same time, the Ilsan New City was planned to have 5 super blocks and 9 neighborhood units. Each life zone was divided by trunk roads. The major characteristic was that each life zone was connected by a green road.

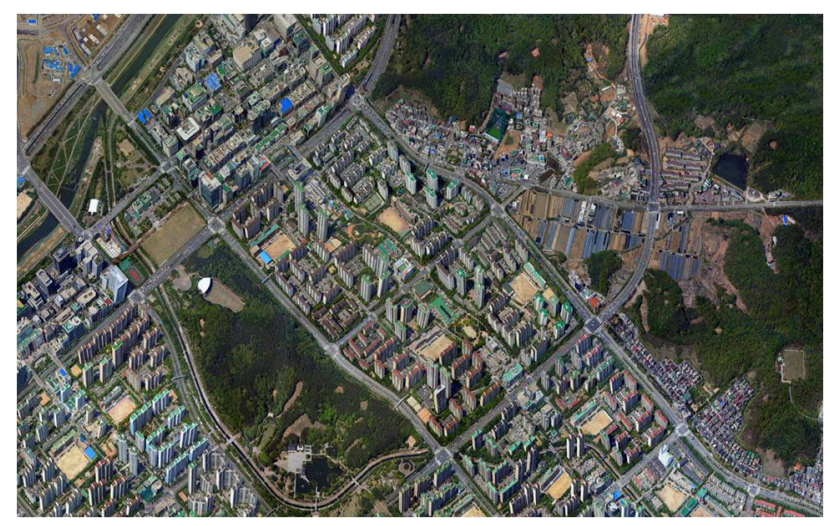

Fig.4. Bird's Eye View of Bundang City

\subsection{Trend of the 21st Century}

It is true that Perry's theory has acted as a major paradigm in the field of housing block and city planning since it was introduced in Korea. However, as planners became aware of the side effects, academic studies and premeditated practices on housing blocks and life zones in city plans were continuously made.

In housing block plans, the spatial configuration of buildings and facilities have been continuously changing, which proves that there have been various 
planned trials. Choi et al. (2013) quantitatively analyzed the changes in spatial configuration in apartment blocks. He analyzed the placement of the complex entrance, retail shops, residential buildings, the playground, exercise facility, park and recreation facility, and the school and changes that occurred in accessibility. The study found that there was a big change in the location of local shops, as they were relocated from the center of the block to the boundary. The Jamsil Blocks 1 to 4 , where Perry's neighborhood unit theory was reflected faithfully, were reconstructed, maintaining the location of the school. After the reconstruction, it was confirmed that the facilities were relocated from the center to the boundary of the block. Such changes support pedestrian activity in the boundary streets, but fail to overcome the exclusivity of the apartment sites. Additionally, as underground parking lots became common, outdoor space planning including landscaping became important.

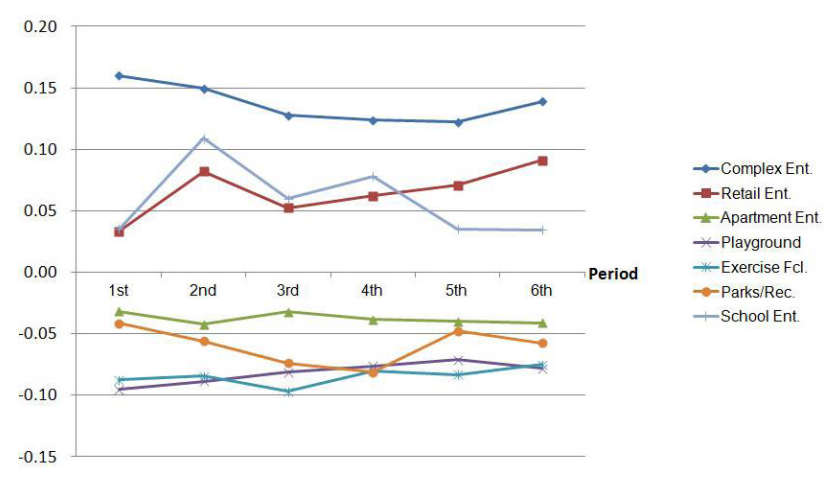

Fig.5. Periodical Trends for Each Spatial Component in Apartment Complexes (Choi et al., 2013)

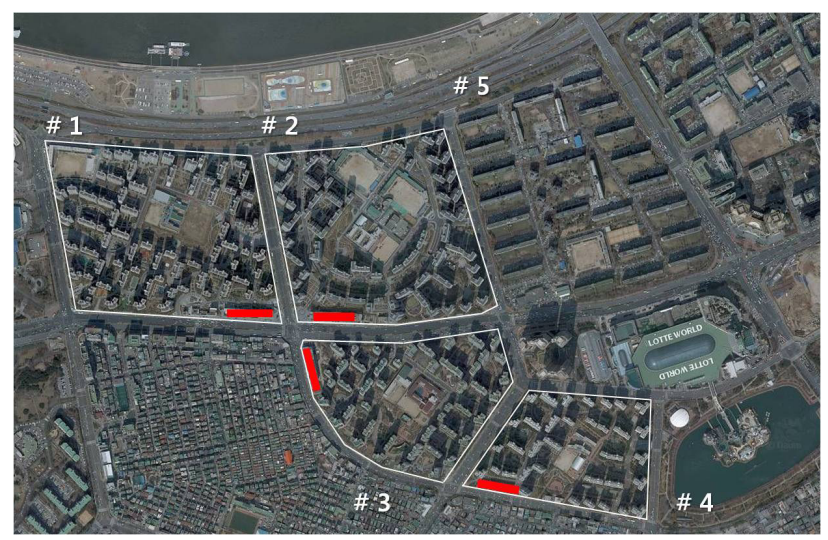

Fig.6. Shop Arrangement in Jamsil Complexes

In the 21 st century, the trend of high-end apartments emerged. Specifically, construction companies made their own apartment brands and plans of convenient facilities and outdoor space became differentiated by brand. This is the result of a combination of well-being practices and the increased demand from residents concerning living environments. This trend resulted in solidifying the exclusiveness of apartments, while various planning strategies were used for the internal pedestrian spaces and amenities.

\section{Perry's Theory: Still Viable in Korea? 4.1 Adaptation in Korea: Apartment Complexes}

Just as in overseas cases, in Korea, neighborhood unit theory has been applied to various new cities and housing block plans as a design principle since it was first introduced. From the 1970 s to 1990 s, when the development of apartment blocks expanded, Perry's theory acted as a strong design paradigm in apartment planning. In block plans, the method "to place the neighborhood center in the residential block, to surround the block with walls, and to make the block exclusive and closed against the street spaces outside of the block" was uniformly applied. (Jeon et al., 2008) During the process, reflection, discussion and evaluation were not made systematically and only restricted planning was made accordingly. In the background of this phenomenon, the amount of supply was focused on without consideration of neighborhood life and economic logic. In other words, in apartment blocks, to which neighborhood unit theory was applied, self-contained life was possible, and such blocks became "an efficient tool to make mass construction of building blocks as a planning unit without considering neighborhood." (Lee et al., 1997, 10)

While the neighborhood unit theory was expanded in Korea, it was realized as a self-contained and closed plan. When planning the life zone plan, it was utilized as a major ground. This is connected to criticisms, which have been raised against Perry's theory before; 1) Unit which only considers physical perspective and excludes social perspectives 2) Composition of a selfcontained and closed community. The main criticisms of Korean apartment blocks concerned the uniformity of physical environments and the closure that severed them from the city space. However, in some cases of general housing blocks and new city plans, we could see the efforts to practice a developed plan concept that compensated for the problems of Perry's theory. In the 1970s and 1980s, the neighborhood unit theory was applied to apartment blocks in Korea with the introduction of a new residential type such as apartments, and the mass supply of houses as a part of the government driven economic development plan. Various New City Plans published in the 1990s to resolve the over-crowdedness of Seoul practiced a new planning concept considering city spaces, although they were based on Perry's theory in the stage of lifezone configuration. Although it is true that there have not been sufficient discussions or evaluations in the case of the neighborhood unit theory, which acted as a strong paradigm, it is also true that customization efforts were made according to Korean situations.

In present Korean apartment blocks, a new community concept is found which is different from that proposed in the original theory. They show a different configuration of neighborhood facilities. Specifically, the introduction of underground parking lots is a major change. Nowadays, they can be accessed 
directly from the apartment buildings and lead to various amenities. Furthermore, underground parking lots allow the ground level to be used for pedestrian activities without the infringement of traffic. Along with the trend of upscale apartments, quality pedestrian spaces materialize as high-end facilities, which is a phenomenon unique to the Korean context. In the next chapter, we will look at how the problems of the neighborhood unit theory as criticized before appear in Korean apartment blocks and how they were solved. The cases were analyzed based on site visits, mainly focusing on pedestrian activities occurring at the site boundaries and the internal open spaces.

\subsection{Implications for the Present}

When looking at the recent trend of housing block plans, it was found that the most remarkable characteristic was the change in spatial configuration such as the change from internal orientation to street orientation. To focus the life in an apartment block toward the inside of the block, it is important to install walls defining the physical boundary and distribute convenience space and facilities at the center of the block. If this tendency is inner-directed, the opposite tendency such as street-directed means that connections are made between the block and street spaces due to trunk roads determining the boundary of the block. The most representative example is the placement of local shops facing toward trunk roads rather than the center of the block. This is different from the past cases following Perry's theory, which placed the community center in the middle of the residential block and maintained accessibility from each house.

In the residential block, it is very important to supply adequate car parking space. The introduction of underground parking lots caused significant changes in apartment block plans. Exterior spaces that were previously used as parking lots became available as common spaces. To secure competitiveness, construction companies advertised their outdoor space plans and such inclination intensified in the 2000s. They tried various landscaping plans such as designing a walking lane, park, small forest, pond, and pool. Afterwards, underground parking and outdoor space were vertically planned and completely separated. In some cases, however, they planned the underground space and ground space to be connected vertically using level differences.

Locating retail shops at the boundary roads has a positive effect on promoting pedestrian activities. However, this does not mean that the apartment site itself is physically open to the public. Open spaces that were made available by installing underground parking lots, on the other hand, fulfill the necessary condition of establishing a pedestrian community within the physical neighborhood unit.

In recent projects such as Banpo Xi (2008) and Raemian Firstage (2009), convenience facilities were planned to be accessed by underground circulation.
This means that a new concept of a community was created, that was different from the concept proposed in the neighborhood unit theory. The following are the spatial program of the community space, intentions of the plan, and community composition method found in the two cases.

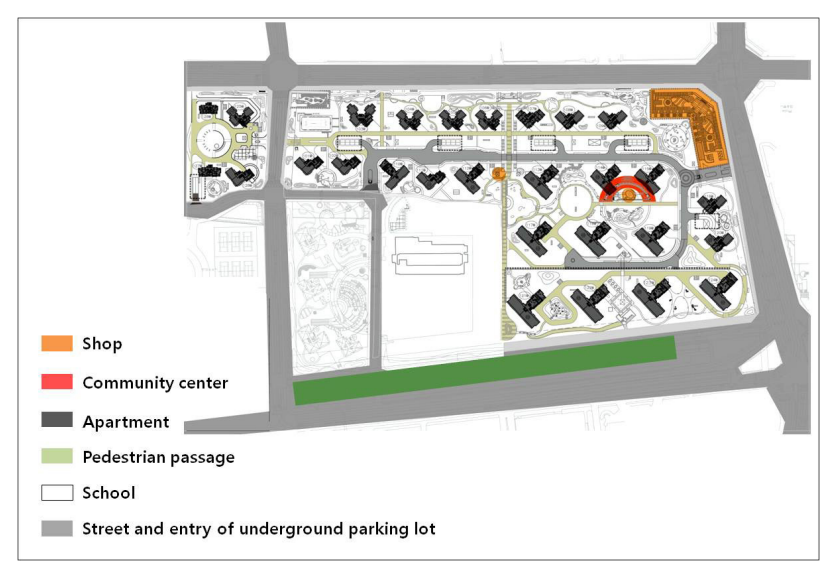

Fig.7. The Raemian Firstage Apartment Complex

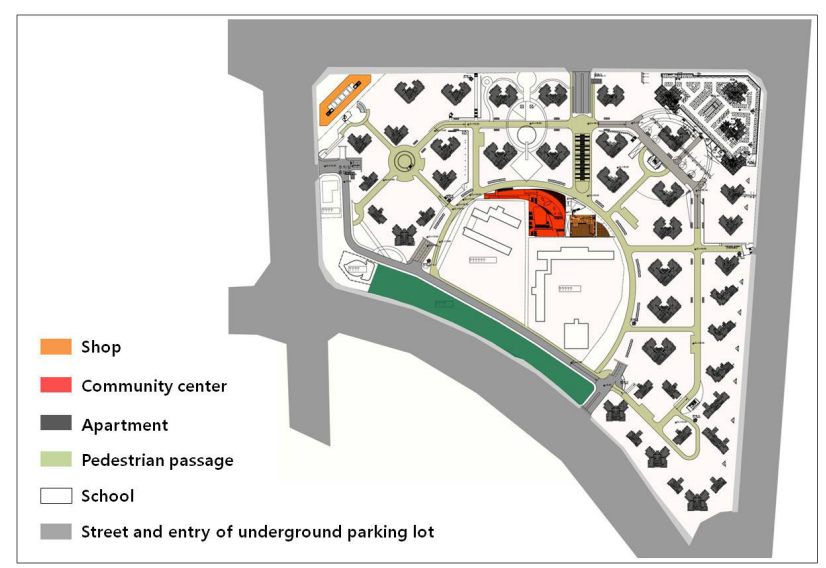

Fig.8. The Banpo Xi Apartment Complex

In the Raemian Firstage, a kid's room, pool, sauna, golf driving range, and book café are placed in the residential community facility called 'Hestia.' The local shops are distributed facing toward the trunk road in a ' $\Gamma$ ' shape. 'Hestia' is the common name of community centers operated by the Raemian brand.

In the Banpo $\mathrm{Xi}$, the block is located on a slope. The underground space is integrated to the residential community facility because of the difference of the level of the site. The main road was planned as a halfcircle placing the elementary school in the center. Facing the main road, there is the Xian Center, the community convenience facility of the block. There is a sunken space beside it. In the basement of the Xian Center, there is a fitness center, sauna, pool, golf driving range, hobby classes, and on the first floor a café, ATM machines, and on the second floor a children's library, reading room and administration office. The local shops are located linearly facing the main road. 
Both cases placed neighborhood local shops facing the main road as a boundary of the block. It is meaningful that they induced the activation of street spaces through landscaping around local shops and the street plan as well as physical connection to street space. The community facility is spatially integrated. Amenities and various facilities in the block are planned in the community center rather than being placed in a building or scattered all over the block as separate buildings. The community center is accessed from the housing blocks at various levels.

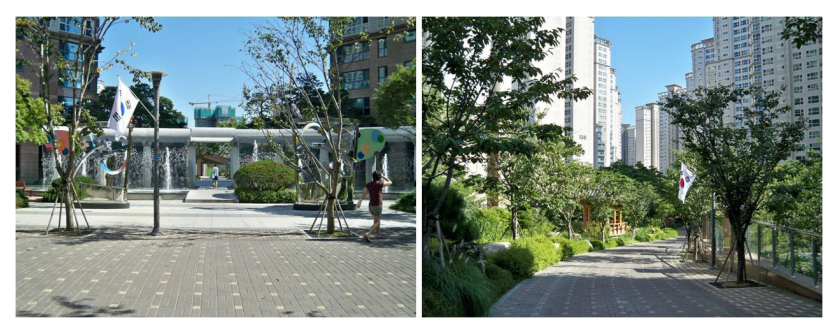

Fig.9. Pedestrian Passage in the Banpo Xi Apartment Complex

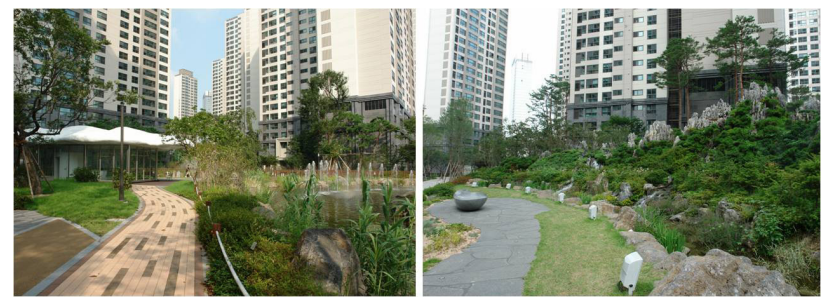

Fig.10. Landscape in the Raemian Firstage Apartment Complex

The cases of the Raemian Firstage complex and the Banpo Xi complex are meaningful because of the following; first, we can find meanings from the method of composition and the community concept. It is different from convenience facility plans in previous apartment blocks in that it included facilities that residents demand, and delicate consideration was applied in the physical design. The community centers of the two blocks symbolize the identity of construction companies and act as a strategy for differentiation. The systematic management and operation of community centers respond to the desire and demands of residents as well as strategic aspects. Second, we can find meaning from the positive utilization of underground space. It was utilized through vertical connection using the difference of levels rather than separated or severed spaces. The community concept and physical plan that compose this concept are shown in the cases of the aforementioned apartment blocks as new and original trails. Relating to this, Jeong (2012) compared phenomena shown in the two blocks focusing on the new behavior such as pedestrian use of the underground. He specified the reasons for pedestrian use of the underground as follows; first, distribution of park, underground parking lot and community facility, second, spatial structure, and third, difference in the concept of underground space and circulative road in the apartment block. He additionally mentioned "if an underground parking lot was the defining characteristic of an upscale apartment in the 1990s, it is now a good communal facility that does so."

The neighborhood unit theory was used not only as a basic design principle but also in a modified form. In Korea, it was used not only in residential areas, but also in large-scale apartment projects with continuous efforts to overcome the criticisms of the theory.

Conclusively, the criticisms raised against the neighborhood unit theory; that the theory only considers physical perspectives and ignores social perspectives, and that the theory promotes a selfcontained closed community have been resolved in the Raemian Firstage complex and the Banpo Xi complex with advanced physical designs such as street oriented spatial configuration and integrated utilization of underground space. The upscale strategies brought to the apartments quality pedestrian environments and communal facilities. This was all made possible by installing underground parking lots, with underground pedestrian movement a byproduct. Locating retail shops along the boundary roads, along with small plazas and parks near the entrances of the apartment complexes should promote pedestrian activities that were restrained in the earlier apartments. However, this should not be confused with relieving the exclusiveness of apartment complexes, but rather understood as creating a buffer between the collectively private apartment site and the public urban districts.

The neighborhood unit theory is effective. From apartment projects that fully adopted the theory, to ones that attempted to solve the negative effects of the theory, to the current upscale apartments, it has been effective in Korean apartments with unique variations.

\section{Conclusion}

The purpose of this study was to verify the validity of the neighborhood unit theory in Korea and to interpret its meaning. We reviewed the major contents and corresponding examples of the neighborhood unit theory, summarized major contents of the controversies and criticisms surrounding the theory, and reviewed how the neighborhood unit theory was introduced and applied.

Korea reached its peak in the 1970s starting with economic growth in the 1960s and experienced a boom in the 1980s. Although it joined the OECD in the 1990s, it also entered an era of austerity due to the foreign currency risk in late 1997 and was overcome in the early 21 st century. Under such social and economic backgrounds, mass supply of houses was made in a short time during which the neighborhood unit theory was extensively used as a strong design paradigm. Conclusively, the neighborhood unit theory still suggests basic design principles to various fields from housing block planning to life zone planning and it is proved to be still useful. Although there was a time when Perry's theory was applied uniformly despite 
the social and economic changes in Korea, there were efforts to overcome such uniformity. Apartment cases were studied focusing on the pedestrian environment in and around the apartment sites. What is interesting is that new community concepts have been created in the trend of Korean apartment Complex plans that is different from that proposed in the original theory and that a new trend has been introduced in the configuration of residents' convenience facilities. Specifically, criticisms that the theory only considers physical perspective and excludes social perspectives and that it composes a self-contained and closed community, have been resolved through fresh trials such as street oriented spatial configuration and the utilization of underground space.

As this study tried to judge the value and usefulness of the neighborhood unit theory by focusing on physical design, it did not deal with the criticism that it can be used as a tool for the discrimination of classes and races.

This study is meaningful in that it re-illuminated the importance of the neighborhood unit theory as a course to search for a new paradigm of housing block planning in Korea. Additionally, this study is valuable in that it diagnosed the usefulness of the theory in Korean housing block plans and interpreted the new planning tendency found in domestic apartment blocks.

\section{References}

1) Banerjee, T. and Baer, W. (1984) Beyond the Neighborhood UnitResidential Environments and Public Policy, Plenum Press, New York, pp.27-28.

2) Choi, J., Kim, M., and Byun, N. (2013) Quantitative Analysis on the Spatial Configuration of Korean Apartment Complexes, Journal of Asian Architecture and Building Engineering, 12(2), pp.277-284.

3) Jeong, L. (2012) A Study on the Pedestrian Usage of the Underground Spaces in Apartment Complexes, Master thesis, Seoul National University, Korea, p.22.

4) Jeon, N., Son, S., Yang, S., and Hong, H. (2008) History of Modern Korean Housing 1: Social History of Korean Housing, dolbegae, p.352.

5) Kang, B., Kang, I., Park, K., Park, I., Park, C., and Baek, H. (1999) History of Planning for Korean Apartment Housing, Sejinsa, Seoul, p.91, p.98.

6) Korea National Housing Corporation (1979), 20 years History of Korea National Housing Corporation, p.459.

7) Korea National Housing Corporation, Case Study on the Construction of Large-scale Housing Block, 26, p.38.

8) Kwon, Y., Jeon, B. (2011) The Time of the Effect of Neighborhood Unit Principle to the Planning of Residential Areas in Seoul in the Japanese Colonial Times, Journal of Architectural Institute of Korea, 27(12), pp.189-201.

9) Lawhon, L. L. (2009) The neighborhood Unit: Physical Design or Physical Determinism? Journal of Planning History, 8(2), pp.111132.

10) Lee, J. (1996) An Analysis of Clarence A. Perry's Neighborhood Unit-Based on the Cases of American Neighborhood Planning, Journal of Architectural Institute of Korea, 12 (5), pp.99-111.
11) Lee, K., Kang, B., Kang, I., Park, K., Park, I., and Park, C. (1997) The Transition and Implication of the Community Planning Concepts in Large-scale Residential Planning in Korea, Journal of Architectural Institute of Korea, 13(10), pp.3-12.

12) Park, C. (2013) Apartment, Mati, p.296.

13) Perry, C. A. (1929) The Neighborhood Unite, Regional Survey of New York and Its Environs VII, Trans. and ed. Lee, Y. as The Neighborhood Unit Theory: How the city became the present, Communication books, 2013, Korea.

14) Perry, C. A. (1939) Housing for the Machine Age. Russell Sage Foundation, New York.

15) Perry, C. A. (1966) The neighborhood Unit Formula, Urban Housing, New York: The Free Press, p.65.

16) Silver, C. (1985) Neighborhood Planning in Historical Perspective, Journal of the American Planning Association, 51(2), pp.161-174. 